\title{
High-quality manufacturing method of complicated castings based on multi-material hybrid moulding process
}

\author{
* Li-min Liu, Zhong-de Shan, Feng Liu, and Dun Lan \\ State Key Laboratory of Advanced Forming Technology and Equipment, China Academy of Machinery Science and Technology Group Co., Ltd., \\ Beijing 100083, China
}

\begin{abstract}
A multi-material hybrid patternless moulding process for complicated castings has been proposed. Moulding sands used in the hybrid moulding process include silica sand, ceramic sand, chromite sand, zircon sand, and steel shot sand. Experimental method was used to study the effects of moulding sands on the temperature field, mechanical properties, and dimensional precision of the iron castings. Under the condition that the wall thickness on different sides of the casting is the same, when the wall thickness is greater than $10 \mathrm{~mm}$, the heat storage capacity of the moulding sands from strong to weak is steel shot sand, zircon sand, chromite sand, ceramic foundry sand, and silica sand. Tensile strength of the obtained castings from high to low is zircon sand, chromite sand, steel shot sand, ceramic sand, and silica sand. Contraction rate of the obtained castings from high to low is steel shot sand, zircon sand, chromite sand, silica sand, and ceramic sand. Therefore, steel shot sand and zircon sand can be used as chilled sand, and even can be used instead of cold iron when the casting wall thickness is greater than $10 \mathrm{~mm}$. Zircon sand and chromite sand can be used to obtain high mechanical properties, and silica sand and ceramic sand can be selected to obtain high dimensional precision of the castings. Finally, a typical iron casting piece was tested by experiment using the hybrid moulding process. Excellent performances of iron castings confirm the feasibility of the hybrid moulding process.
\end{abstract}

Key words: hybrid patternless moulding process; hybrid moulding process; thermal physical parameters; temperature field; mechanical properties; dimensional precision
CLC numbers: TG221 .1
Document code: $\mathrm{A}$
Article ID: 1672-6421(2018 05-343-08

$\mathrm{H}$ igh-quality complicated castings are indispensable for high-end equipment used in national defense and aviation industries. There are a series of problems in traditional foundry technology, including long process cycle, poor accuracy control of shape and property, and the incapability of incorporating merits of various foundry technologies, so that the castings are either high in accuracy but with defects, or flawless but without due accuracy. Different local thicknesses of the sand mould result in different thermal physical parameters and shrinkage, and eventually lead to great differences in local microstructure and mechanical properties or lower dimensional accuracy of the castings. Since traditional foundry technologies cannot satisfy the urgent needs for high-precision and high-performance castings, new casting methods and technologies are needed.

\footnotetext{
*Li-min Liu
}

Female, Ph.D. Her research interests mainly focus on advanced manufacturing technology and equipment.

E-mail: liu_limin05@163.com

Received: 2018-04-23; Accepted: 2018-07-30
To solve the problems mentioned above, this study innovatively puts forward a new technology called hybrid moulding, in which multi-moulding sands were used, based on the patternless moulding process, as shown in Fig. 1. This new moulding process can flexibly dissect the mould into different units and make these units with different moulding sand materials according to the casting structural features. The mould units can be obtained through digital cutting sand billets or 3D printing, and then assembled together to form the final mould. This new process has greatly improved the flexibility in mould design, and allow high-performance, high-quality and structurally-excellent castings to be manufactured, which are far from available through traditional foundry technologies ${ }^{[1-4]}$.

The moulding sands used in the hybrid mould process include silica sand, ceramic sand, chromite sand, zircon sand, and steel shot sand. The effects of moulding sands on the solidification rate, mechanical properties, and contraction rate of the castings with different wall thicknesses have been studied. Moulding sand selection criteria has been proposed based on the hybrid moulding 


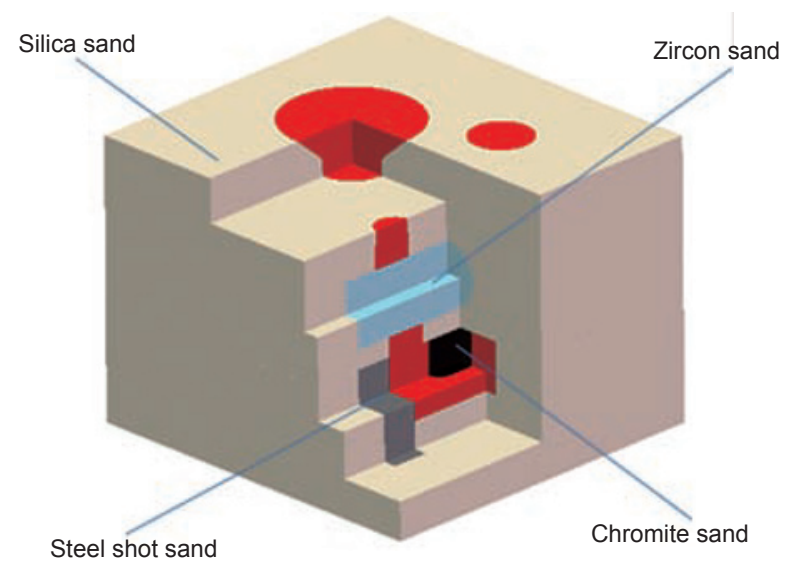

Fig. 1: Schematic diagram of multi-material hybrid moulding process

process to obtain high quality, high performance, and high precision castings. Finally, a comparison is made between the hybrid and the traditional moulding process based on a typical iron casting.

\section{Permeability, gas-forming property and thermal physical parameters of moulding sands}

The 70 mesh/140 mesh three-screen sand was used as raw sand. The alkaline phenolic resin content was $1.5 \mathrm{wt} . \%-3.5 \mathrm{wt} . \%$ of raw sand, and the curing agent content was $15 \mathrm{wt} . \%-35 \mathrm{wt} . \%$ of resin.

The quality of moulding sand directly determines the quality of castings in casting production. The permeability and gas-

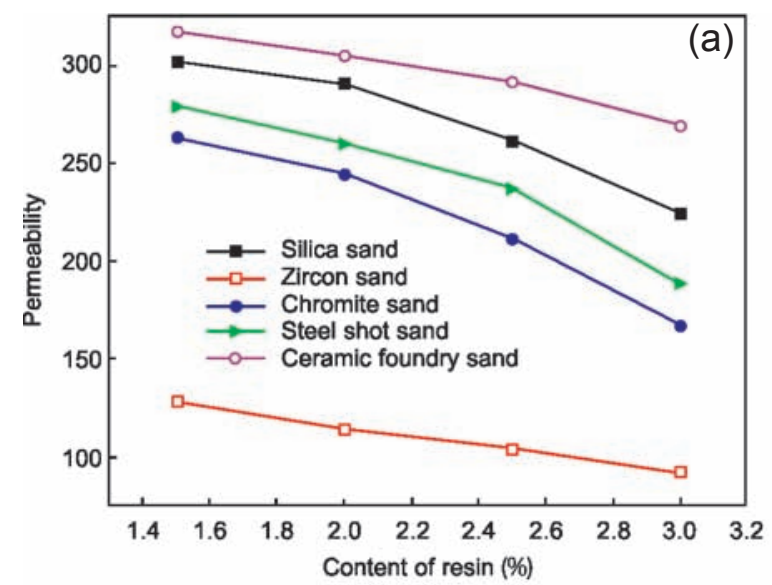

forming properties of moulding sand are the main parameters measuring the sand quality ${ }^{[5]}$. Thermal physical parameters of the moulding sands can provide an evaluation basis for heat storage capacity. The main thermal physical parameters of the researched moulding sands were measured using experimental methods. These thermal parameters include density, specific heat capacity, thermal conductivity, and interfacial heat transfer coefficient.

\subsection{Permeability of moulding sands}

The ZIY-type smart gas permeability tester was used to test the sand permeability. As shown in Fig. 2, with the increase in the contents of resin and curing agent, the permeability of all kinds of moulding sands decreases. Besides, the effect of resin content on the permeability of moulding sand is more obvious than that of curing agent. The permeability of ceramic sand is the highest, followed by silica sand, and zircon sand is the lowest. This is because the shape of ceramic sand is nearly spherical, and its specific surface area is larger than silica sand, so the quantum of resin per unit volume is relatively small, but the clearance among sand is relatively large. Therefore, the gas permeability of ceramic sand is higher than that of silica sand. The shape of most steel shot sands is spherical, but their specific gravity is large, and the quantum of resin per unit volume is great, so the permeability is poorer than that of ceramic sand and silicon sand. The particle shape of chromite sand is similar to silica sand, but its specific gravity is relatively higher. Therefore, its permeability is poorer than that of silica sand. The particle shape of zircon sand is poorer than chromite sand. The mosaicism of the large and small particles is evident, leading to fewer direct channels of sand and consequently greatly reducing the permeability of zircon sand, so its permeability is the lowest ${ }^{[5]}$.

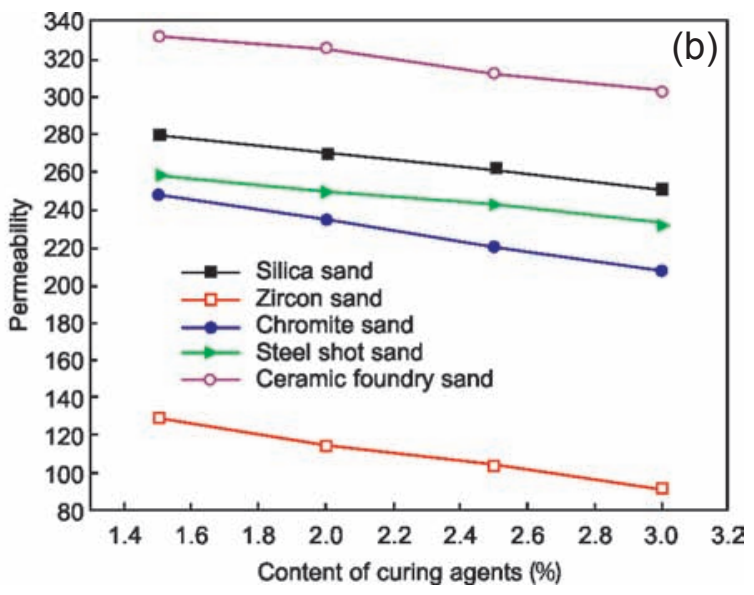

Fig. 2: Influence of resin (a) and curing agent (b) content on permeability of sand

\subsection{Gas evolution of moulding sands}

The ZY-II type smart gas evolution tester is used to test the gas evolution of the sand. As shown in Fig. 3, the amount of gas evolution of moulding sand rises rapidly with an increase in contents of resin and curing agent. The effect of resin content on the amount of gas evolution is more evident than that of curing agent. Theoretically, when the added mass fraction of resin and curing agent is the same, the amount of gas evolution of moulding sand shall be equal. However, the amount of gas evolution of different moulding sands from small to large is chromite sand, ceramic sand, silica sand, zircon sand and steel shot sand. This is because various types of sand contain different chemical substances and impurities that affect their gas evolution $^{[5]}$. 

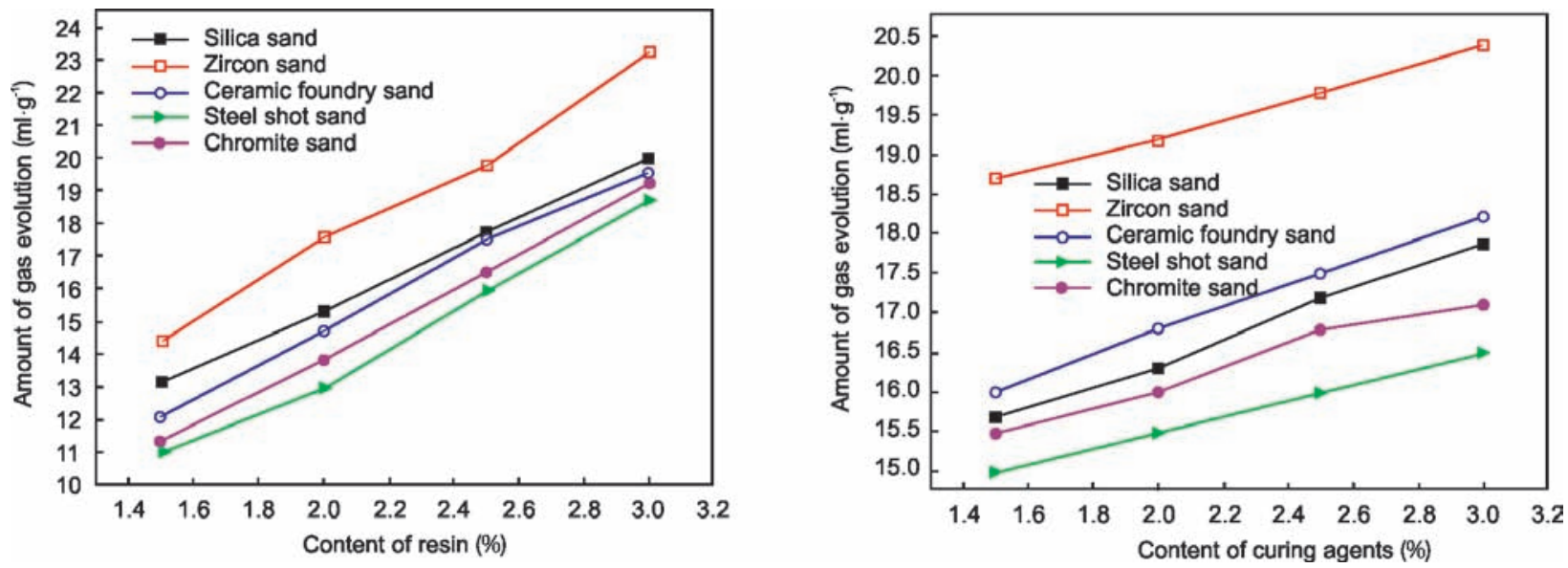

Fig. 3: Influence of resin (a) and curing agent (b) content on gas evolution of moulding sand

According to the study on tensile strength and castability of the five moulding sands, optimal contents of resin and curing agent of different moulding sands based on patternless casting manufacturing technology have been obtained (Table 1$)^{[6]}$.

\subsection{Thermal physical parameters of moulding sands}

The measured densities of the five moulding sands are shown in Table 2.

Table 1: Optimal resin and curing agent contents of different moulding sands ${ }^{[6]}$

\begin{tabular}{|lccccc}
\hline Raw material (wt.\%) & Silica sand & Ceramic sand & Chromite sand & Zircon sand & Steel shot sand \\
\hline Resin (weight percent of raw sand, \%) & 2.5 & 1.5 & 2 & 2.5 & 2 \\
Curing agent (weight percent of resin, \%) & 20 & 25 & 20 & 25 & 20
\end{tabular}

Table 2: Density of moulding sands $\left(\mathrm{g} \cdot \mathrm{cm}^{-3}\right)$

Moulding sands

Density $\left(\mathrm{g} \cdot \mathrm{cm}^{-3}\right)$
Silica sand

1.158

\section{Ceramic sand Chromite sand}

\section{Zircon sand Steel shot sand}

1.352

2.176

2.231

3.126

Specific heat capacity and thermal conductivity of the moulding sands were measured using a transient method (laser method $)^{[7-9]}$. Interfacial heat transfer coefficient of the moulding sands has been measured using heat conduction temperature measurement method ${ }^{[10]}$. The results are shown in Figs. 4 to 6 .

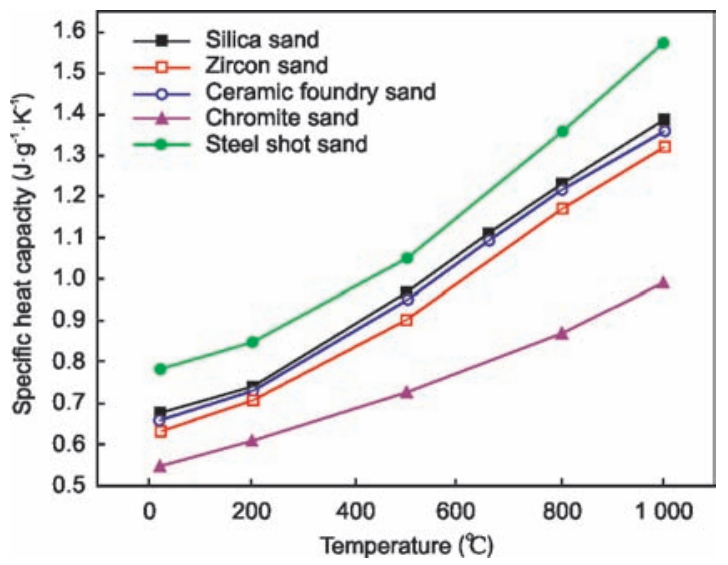

Fig. 4: Specific heat capacities of five moulding sands

It can be seen from Fig. 2 through 4 that specific heat capacity, thermal conductivity, and interfacial heat transfer coefficient of the five moulding sands increase with the increase

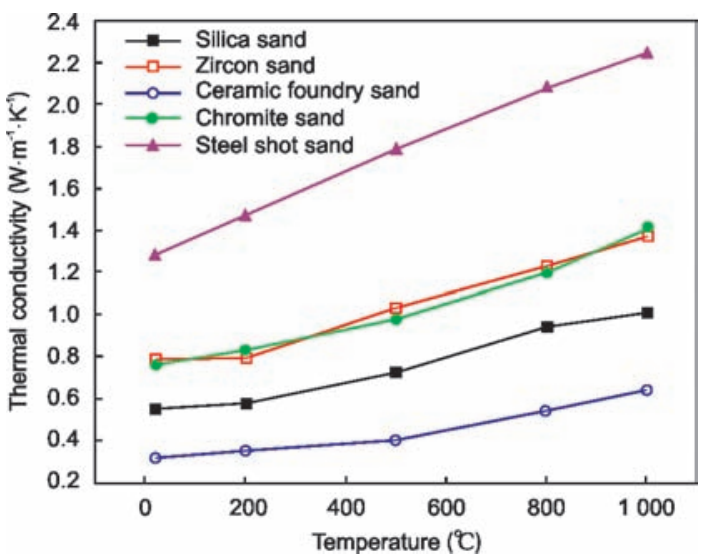

Fig. 5: Thermal conductivities of five moulding sands

of temperature. Specific heat capacity from high to low are chromite sand, ceramic sand, silica sand, zircon sand, and steel shot sand, while the thermal conductivity of the five moulding sands from high to low is the opposite of specific heat capacity. When the temperature is higher than $800{ }^{\circ} \mathrm{C}$, the interfacial heat transfer coefficients from high to low are steel shot sand, zircon sand, chromite sand, ceramic sand, and silica sand. When the temperature is lower than $700{ }^{\circ} \mathrm{C}$, interfacial heat transfer coefficient of the five moulding sands is approximately 


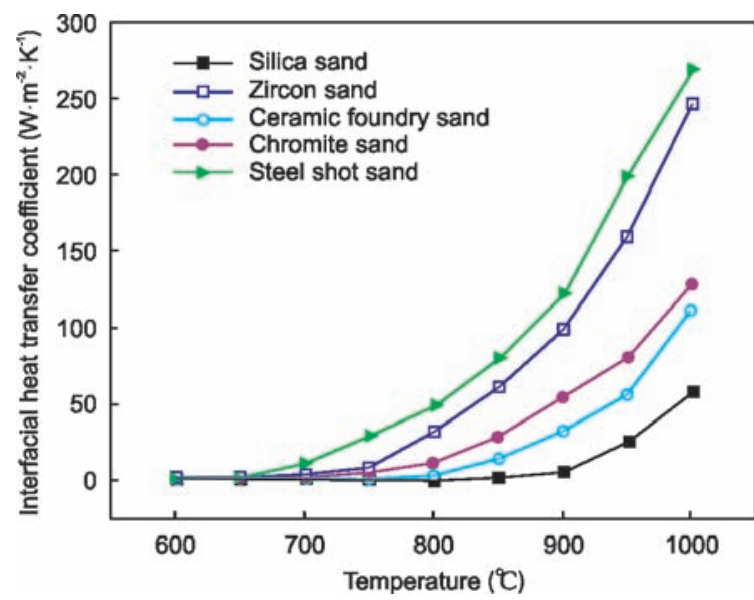

Fig. 6: Interfacial heat transfer coefficient of five moulding sands

the same. When the temperature is between $700-800{ }^{\circ} \mathrm{C}$, the interface heat transfer coefficients of silica sand and ceramic sand is similar. The reason is that the difference temperature between castings and sand mould decreases with the decrease of casting temperature, leading to the interface gap gradually emerging. Also, the interface convection and radiation heat transfer decrease with the increase of interface gap. When the casting temperature is lower than $600{ }^{\circ} \mathrm{C}$, the thermal equilibrium of the casting/mould interface will be reached.

\section{Effects of moulding sands on properties and dimensional precision of iron castings with different wall thicknesses}

Different moulding sands possess different heat storage capacities, thermal parameters, and chemical compositions, so the quality, performance, and dimensional precision of the castings are also different when different moulding sands are used. The cylinder HT250 gray iron castings with different wall thicknesses are taken as an example. An experiment was carried out to study the effect of moulding sands on the solidification rate, mechanical properties, and contraction rate of the iron castings with different wall thicknesses $(5,8,10,15$ and 20 $\mathrm{mm})$. The pouring temperature was $1,450{ }^{\circ} \mathrm{C}$. Top gating method was used, and there was no riser.

\subsection{Effect of moulding sands on solidification rate of castings}

The heat storage capacity of the sand mould has a great effect on the solidification rate of castings. If the heat storage capacity of mould is stronger, the casting will solidify faster and the temperature gradient of the casting section is greater ${ }^{[11,12]}$. In the casting solidification process, the overall solidification mode depends on the local solidification rate. Furthermore, the overall solidification mode is the critical factor to determine the microstructure, overall quality, and performance of the castings. In this study, the solidification time of the castings was tested by the pre-embedded thermocouple method, and the solidification time of the castings with different wall thicknesses and different moulding sands was shown in Fig.7.

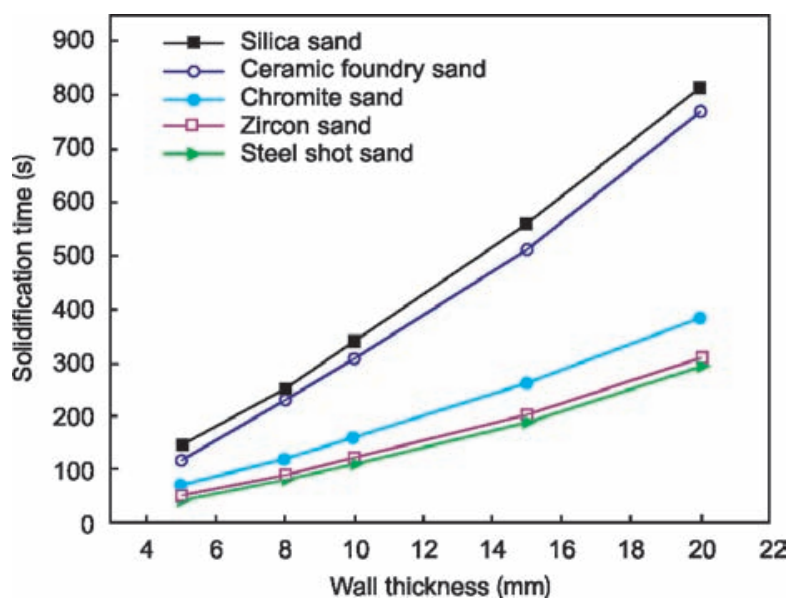

Fig. 7: Solidification time of castings with different wall thicknesses and different moulding sands

When the casting wall thickness is less than $10 \mathrm{~mm}$, the heat storage capacity of silica sand and ceramic sand are approximately the same, while that of steel shot sand, zircon sand, and chromite sand are similar. When the casting wall thickness is no less than $10 \mathrm{~mm}$, the solidification time to reach the solidus of the castings with different moulding sands, respectively are: steel shot sand (96-247 s), zircon sand (101-265 s), chromite sand (139-338 s), ceramic foundry sand (275-720 s), and silica sand (314-761 s). The heat storage capacity of the five moulding sands from strong to weak are: steel shot sand, zircon sand, chromite sand, ceramic sand, and silica sand.

\subsection{Effect of moulding sands on microstructure and tensile strength of castings}

In the solidification process, there is a heat exchange between the casting and the mould. As the other conditions remain unchanged, the temperature gradient of the casting will be in a wide variety when different moulding sands are used. Thus, the microstructure will be diversified, resulting in different mechanical properties of castings ${ }^{[13]}$. The graphite lengths of the iron castings with different wall thicknesses and moulding sands, tested using an optical mocroscope, are shown in Fig. 8. The tensile strength of the iron castings, tested by universal testing machine, is shown in Fig. 9.

It can be seen from Figs. 8 and 9 that graphite length increases while the tensile strength decreases with the increase of casting wall thickness. When the wall thickness is $5 \mathrm{~mm}$, graphite length is $60-140 \mu \mathrm{m}$, rating for level 5 . When the wall thickness is 10 $\mathrm{mm}$, graphite length is $160-250 \mu \mathrm{m}$, rating for level 4 . When the wall thickness is $20 \mathrm{~mm}$, the graphite is the coarsest.

The solidification rate has great effects on graphite morphology and length. The solidification rate of castings with smaller wall thickness is higher and the degree of supercooling is greater, so the graphite is thinner. In contrast, the solidification rate of castings with greater wall thickness is slower and the 


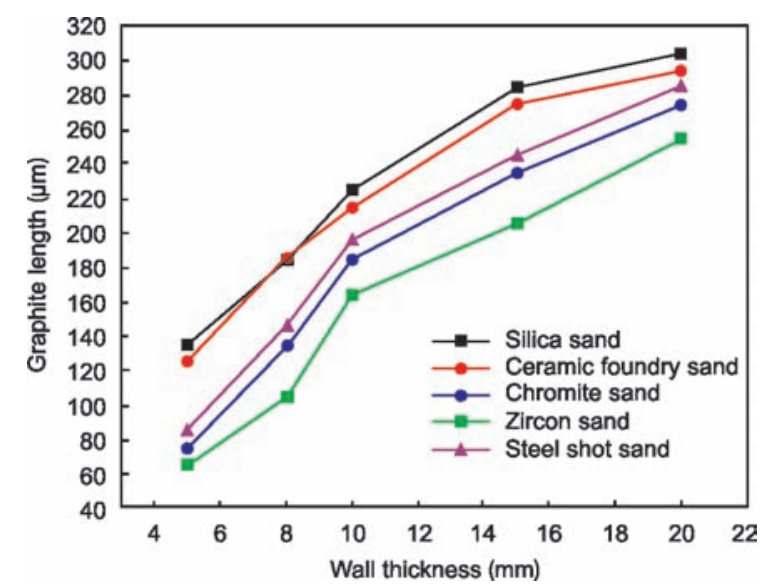

Fig. 8: Graphite length of iron castings with different wall thicknesses and moulding sands

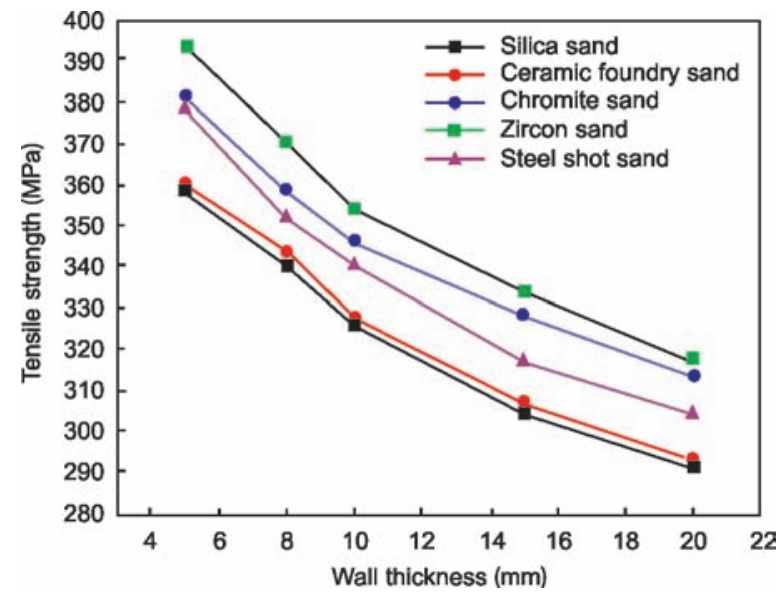

Fig. 9: Tensile strength of iron castings with different wall thicknesses and moulding sands

degree of supercooling is smaller, so the graphite is thicker. When the wall thickness of the castings is $5-20 \mathrm{~mm}$, tensile strengths of the castings are: 356-285 MPa (ceramic sand), 362$281 \mathrm{MPa}$ (silica sand), 375-315 MPa (chromite sand), 394-328 MPa (zircon sand), 370-307 MPa (steel shot sand). The tensile strengths of the castings from high to low are zircon sand, chromite sand, steel shot sand, ceramic sand and silica sand.

\subsection{Effect of moulding sands on contraction rate of casting}

Casting contraction rate is related to the alloy type, the structure of the casting, and the moulding materials ${ }^{[14]}$. During the solidification process, alloy composition, complexity of casting structure, and withdrawing capability of the moulding material can all lead to different casting contraction rates ${ }^{[15]}$. Contraction rate of the iron castings with different wall thicknesses and different moulding sands, tested by laser 3D scanner, is shown in Fig. 10.

It can be seen in Fig. 10 that when the casting wall thickness is less than $10 \mathrm{~mm}$, the contraction rate of the iron casting increases with the increase of wall thickness. However, as the casting wall thickness is bigger than $10 \mathrm{~mm}$, the contraction rate of the iron casting decreases with an increase in wall thickness. The contraction rates of the castings respectively are: $2.16 \%$ $2.34 \%$ (ceramic sand), $2.31 \%-2.43 \%$ (silica sand), $2.96 \%-3.23 \%$ (chromite sand), 3.12\%-3.34\% (zircon sand), and 3.64\%-

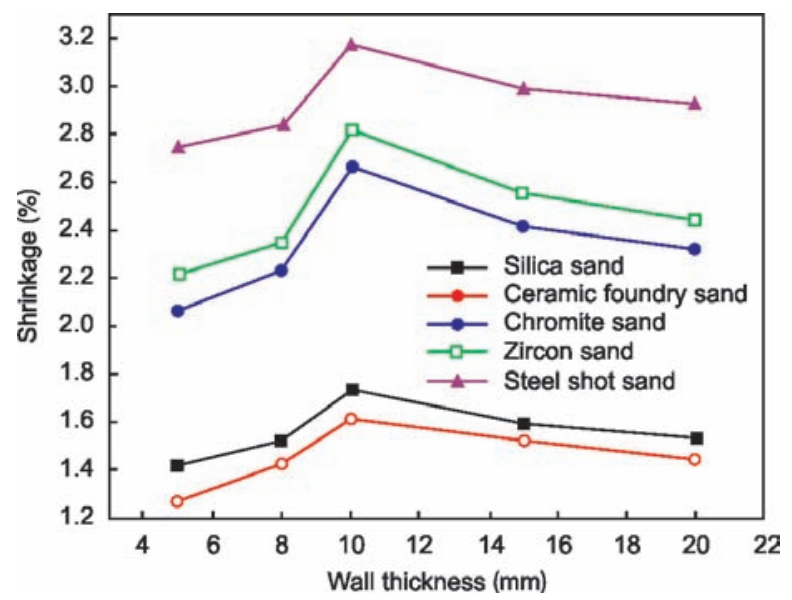

Fig. 10: Contraction rate of iron castings with different wall thicknesses and moulding sands

$3.82 \%$ (steel shot sand). Contraction rates of the castings from large to small are steel shot sand, zircon sand, chromite sand, silica sand and ceramic sand. The reason is that the shrinkage of the castings is associated with the casting's cooling rate and deformability. The lower cooling rate can obtain smaller shrinkage. The cooling rate of the steel shot sand is the highest, and that of the ceramic sand is the lowest. Therefore, the shrinkage of the castings produced by steel shot sand is the largest, and by ceramic foundry sand is the smallest.

\subsection{Moulding material selection criteria based on hybrid moulding process}

Based on the proposed hybrid moulding process, large complex castings can be split into small mould units according to the casting structure. For each mould unit, a different moulding material is selected, so that different portions of the casting can be set at different contraction rates. In this way, castings with high quality and high dimensional precision can be obtained. The following moulding material selection criteria have been obtained according to the above research results.

(1) In terms of the cooling rate during solidification process, steel shot sand and zircon sand can be used as chilled sand. They can even be used instead of cold iron when the casting wall thickness is greater than $10 \mathrm{~mm}$.

(2) Zircon sand and chromite sand can be selected to obtain high mechanical properties of the castings.

(3) Sodium silicate sand and ceramic sand can be selected to obtain castings with high dimensional precision.

In summary, moulding material selection criteria based on the hybrid mould process can provide reference for the design of casting process. With these references, proportional solidification of the castings can be achieved. Castings with high mechanical properties and high dimensional precision can also be obtained.

\section{Case study}

An iron engine shell for a certain ship (Fig.11) was selected as the test piece for experimental validation. For comparison, the traditional casting was also carried out under the same conditions. The maximum boundary dimensions of the shell are 


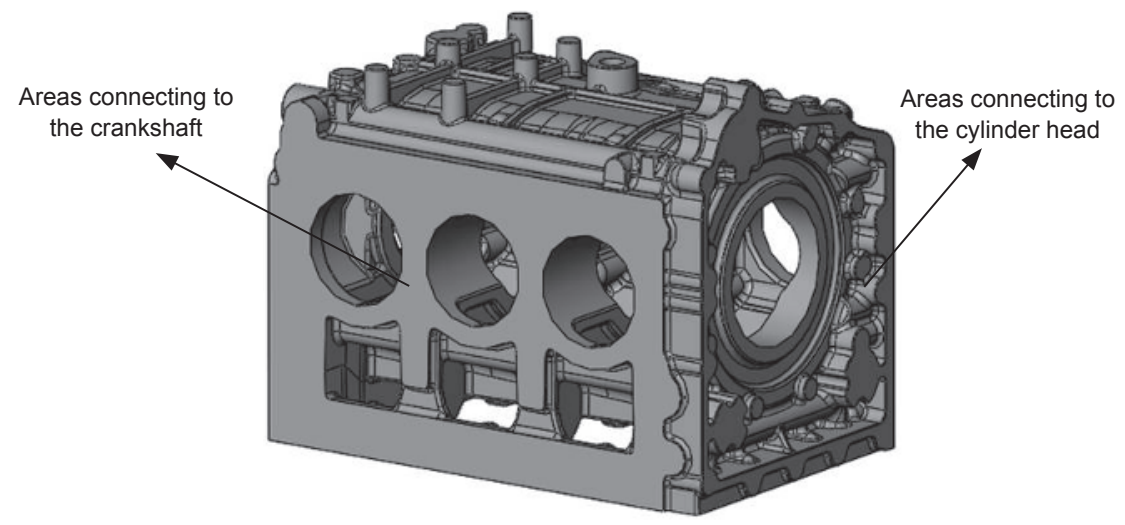

Fig. 11: 3D diagram of engine shell

$754 \mathrm{~mm} \times 603 \mathrm{~mm} \times 472 \mathrm{~mm}$. The thickest wall is about $55 \mathrm{~mm}$, and the thinnest wall is $8 \mathrm{~mm}$. There is a very large difference in wall thickness. The shell is an important component of the engine, and the parts connecting to the cylinder head and crankshaft (Fig.11) of the castings are required to have high strength and dimensional accuracy. Moreover, the overall performance of the casting needs to be uniform and stable. In view of the complicated shape of the shell and uneven wall thickness, combined with the characteristics of patternless hybrid mould process, the whole mould was designed to split into 9 sand units. Considering the large heat storage coefficient of zircon sand and chromite sand, zircon sand was applied in the part connecting to the cylinder cover (at thick wall). Meanwhile, in considering that chromite sand has anti-stick properties to allow for easy cleaning of the sand core ${ }^{[5]}$, low surface roughness of castings, chromite sand is applied in 3 cores at the thick wall of the middle cavity. The remaining sand mould units were prepared using silica sand. The schematic diagram of the hybrid mould is shown in Fig. 12.

All sand mould units are cut and machined on the digitalized patternless casting precision forming machine, and then all units are assembled into the mould to be poured, as shown in Fig. 13. Pouring is made after the temperature of the melted iron reaches $1,430{ }^{\circ} \mathrm{C}$. After the shell casting has been obtained, a test is performed on the graphite morphology and tensile strength

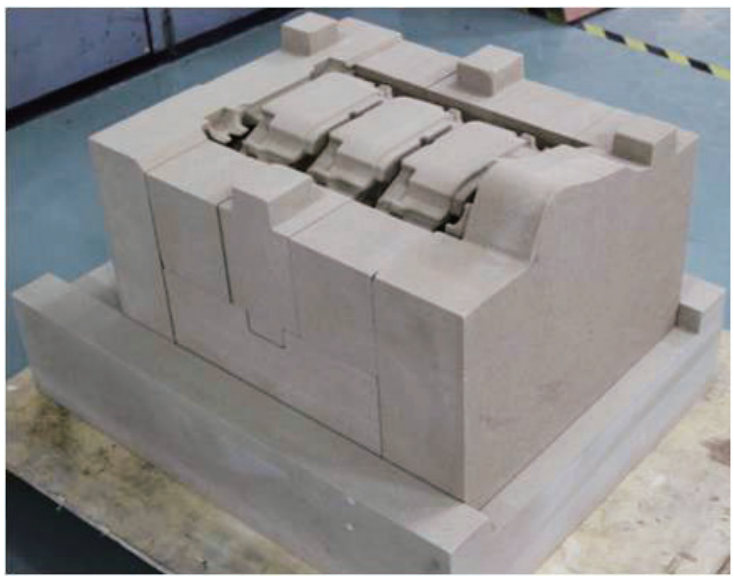

(a) Traditional casting

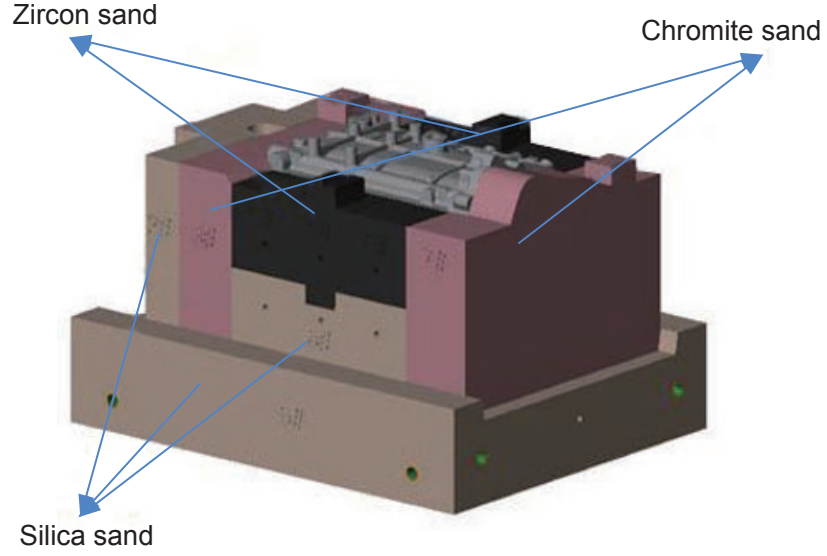

Fig. 12: Schematic diagram of hybrid mould of engine shell

in the important areas: connecting to the crankshaft and the cylinder head.

It can be seen from Figs. 14 and 15 that the graphite morphology is Type A in the area connected with the crankshaft of the engine shell by the traditional casting process, and the graphite size is about $150-200 \mu \mathrm{m}$. In the same position of the casting by the hybrid mould process, the graphite is also Type A, but its distribution is more uniform, and the grain size is smaller, about $50-150 \mu \mathrm{m}$. The graphite morphology is Type $\mathrm{A}+\mathrm{C}$ at the area connecting to the cylinder head by the traditional casting

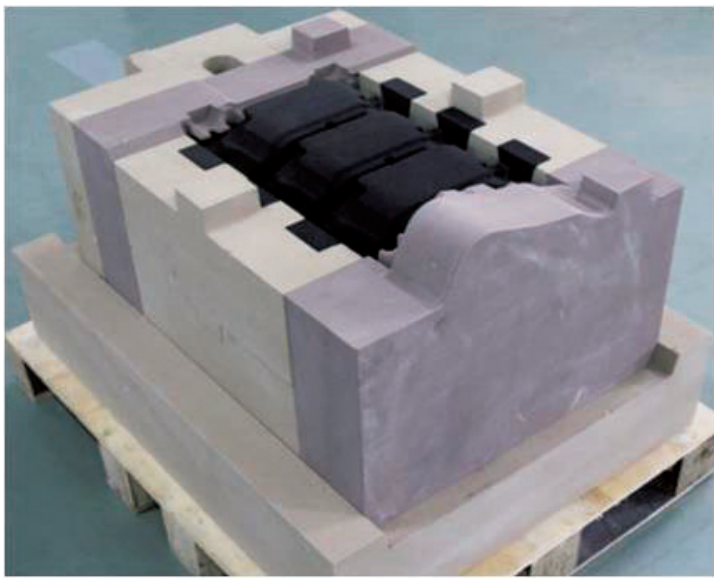

(b) Hybrid mould

Fig. 13: Casting obtained after cutting and assembling 


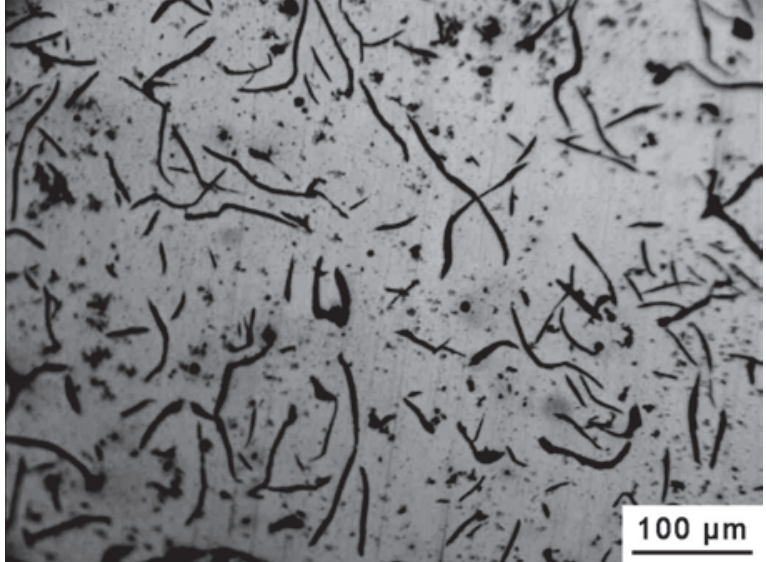

(a) Traditional casting process

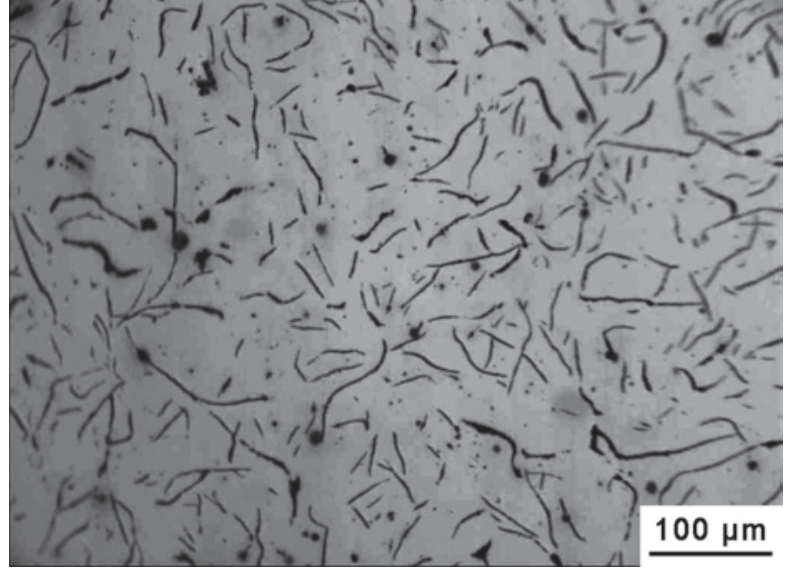

(b) Hybrid mould process

Fig. 14: Graphite morphology at the area connection to crankshaft

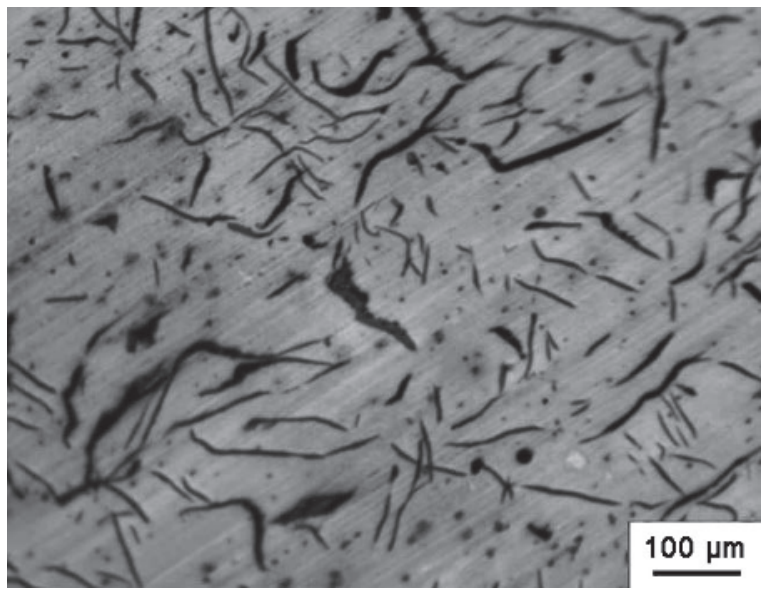

(a) Traditional casting process

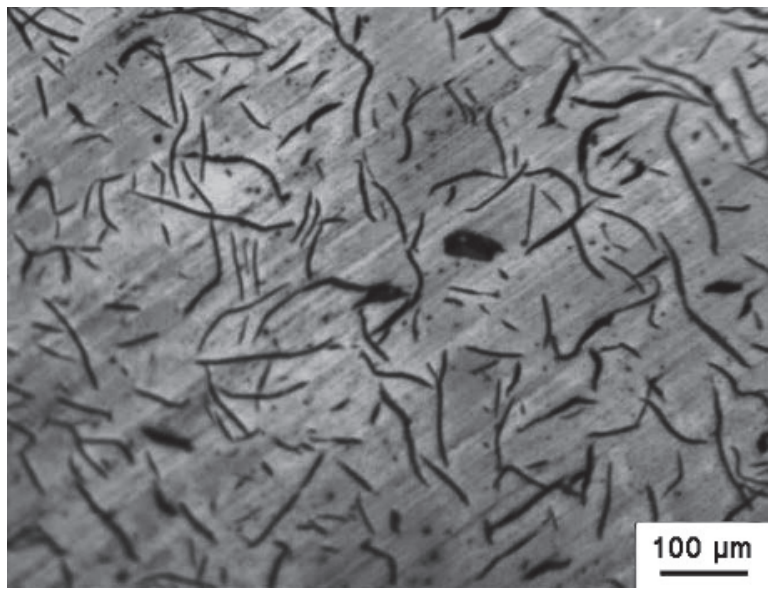

(b) Hybrid mould process

Fig. 15: Graphite morphology at area connection to cylinder head

process. The distribution of the graphite is uneven and there is a small quantity of blocky graphite of about $150-250 \mu \mathrm{m}$ long. However, the graphite morphology is Type A at the area connecting to the cylinder head by the hybrid mould process, and its distribution is relatively uniform with a smaller size of about $100-200 \mu \mathrm{m}$, and no blocky graphite was found.

The reason is that the wall thickness in the area connecting to the crankshaft is about $20 \mathrm{~mm}$, and that at both sides of the connection to the cylinder head is about $55 \mathrm{~mm}$ at most. The solidification rate of silica sand in the traditional process is slower. In the hybrid mould process, the application of chromite sand and zircon sand with a greater heat storage coefficient accelerates the solidification rate of the area and makes the supercooling degree much higher, so the size of graphite accordingly decreases and its distribution becomes uniform ${ }^{[16]}$.

Figure 16 shows that the tensile strength of the area connecting to the cylinder head in the traditional casting process is about $227-230 \mathrm{MPa}$, and that of the area connection to the crankshaft is about 267-268 MPa. However, it is about 270-273 MPa and 312-316 MPa for the casting by hybrid mould process, increased by $15.98 \%$ and $16.4 \%$, respectively, compared with that by the traditional casting process.

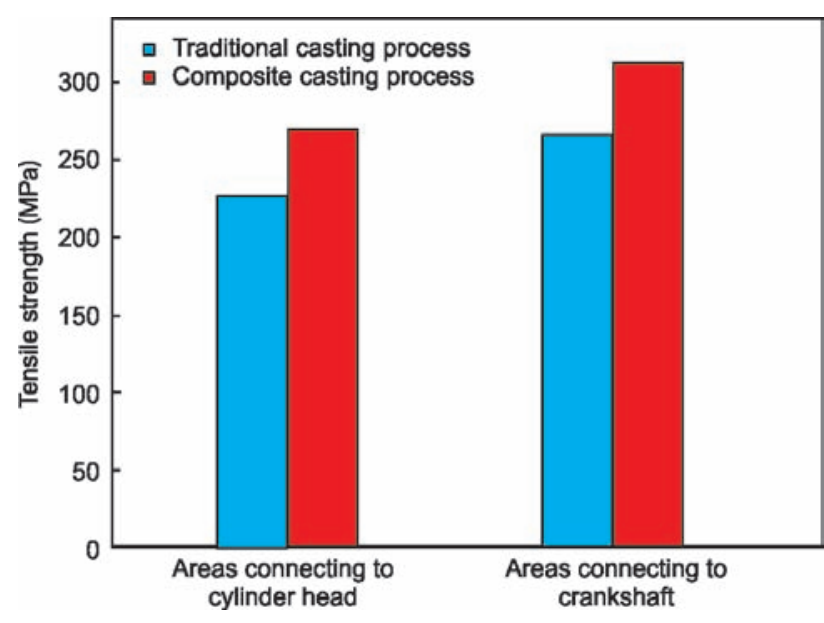

Fig. 16: Tensile strength of the important positions in engine shell

The reason is that the larger the size of graphite, the more uneven the distribution, and the gap effect of graphite will become more obvious. Therefore, the tensile strength of the cast iron by traditional process is lower. Oppositely, for the casting by hybrid mould process, the size of graphite is smaller, and the 
distribution is more uniform, consequently the tensile strength is higher.

\section{Conclusions}

The moulding sands used in the hybrid mould process include silica sand, ceramic foundry sand, chromite sand, zircon sand, and steel shot sand. The effects of moulding sands on temperature field, mechanical properties, and dimensional precision of castings were studied. A moulding material selection criteria based on the hybrid mould process was proposed. The following conclusions can be made:

(1) Under the condition that casting wall thickness of different sides is the same, when the wall thickness is greater than 10 $\mathrm{mm}$, the heat storage capacity of the moulding sands from strong to weak are steel shot sand, zircon sand, chromite sand, ceramic sand and silica sand. Tensile strength of the obtained castings from high to low are zircon sand, chromite sand, steel shot sand, ceramic sand and silica sand. Contraction rate of the obtained castings from large to small are steel shot sand, zircon sand, chromite sand, silica sand and ceramic sand.

(2) A moulding material selection criteria is proposed to obtain high performance, high dimensional precision, and high quality iron castings. Steel shot sand and zircon sand can be used as chilled sand, they can even be used instead of cold iron when the casting wall thickness is greater than $10 \mathrm{~mm}$. Zircon sand and chromite sand can be selected to obtain high mechanical properties of the castings. Silica sand and ceramic sand can be selected to obtain high dimensional precision.

(3) Experimental verification of an engine shell casting shows that according to the moulding material selection criteria, excellent performances of the iron casting can be obtained based on the hybrid mould process.

In summary, the results of this study can provide technical reference for the hybrid mould process to obtain complex iron castings with high performance, high dimensional precision, and high quality.

\section{References}

[1] Shan Zhongde, Liu Feng, Li Xinya, et al. Advanced Manufacture Technology Center China Academy of Machinery Science \& Technology. An adaptive method for casting moulds. China Patent, ZL200910162301.3, 2013.01.09.
2] Shan Z, Yan Y, Zhang R, et al. Rapid Manufacture of Metal Tooling by Rapid Prototyping. International Journal of Advanced Manufacturing Technology, 2003, 21: 469-475.

[3] Hae-Sung Yoon, Jang-Yeob Lee, Hyung-Soo Kim, et al. A comparison of energy consumption in bulk forming, subtractive, and additive processes: Review and case study. Int. J. Precision Engineering and Manufacturing, 2014, 1 (3): 261-279.

[4] Shan Zhongde, Qin Shaoyan, Liu Qian, et al. Key Manufacturing Technology \& Equipment for Energy Saving and Emissions Reduction in Mechanical Equipment Industry. Int. J. Precision Engineering and Manufacturing, 2012, 13 (7): 1095-1100.

[5] Casting Manual, Volume 4: Moulding Material. Foundry Institution of Chinese Mechanical Engineering Society, Beijing: China Machine Press, 2002.

[6] Liu Limin, Shan Zhongde, Lan dun, et al. Research of Cutting Properties of Mould Sand Based on the Precision Forming Technology Without Pattern. Foundry, 2016,12: 1167-1171. (In Chinese)

[7] Kubo K, Ppehlke R D. Thermal properties of moulding sands. AFS Transactions, 1985.

[8] Cristina Sánchez López de Pablo, José Javier Serrano Olmedo, Alejandra Mina Rosales, et al. A method to obtain the thermal parameters and the photothermal transduction efficiency in an optical hyperthermia device based on laser irradiation of gold nanoparticles. Nanoscale Research Letters, 2014, 9(1): 441-446.

[9] Zhang Lin, Du Bin, Lu Yanping. Study on the Method of Accurate Measurement of Specific Heat Using Laser Flash Apparatus. Vacuum Electronics, 2015, 2: 41-45.

[10] Kang Jinwu, You Rui, Nie Gang. An indirect surface temperature measurement method in the casting process of large castings. China Patent, ZL201110388031 2011.11.29. (In Chinese)

[11] Bazhenov V E, Koltygin A V, Fadeev A V. The use of the ProCast software to simulate the process of investment casting of alloy based on titanium aluminide TNM-B1 into ceramic moulds. Russian Journal of Non-Ferrous Metals, 2014, 551-555.

[12] Xu Zunping, Qiang Hua. Finite element simulation of temperature field of ZL105 alloy sample in solidification process under different mould. Hot Working Technology, 2008, 17: 1315. (In Chinese)

[13] Hou Qifei, Yang Juan, Wang Liuli. The effect of graphite morphology and oxide inclusions on the mechanical properties of gray iron castings. China Foundry, 2010, 31(5): 302-304.

[14] Chen Bingxi. Contraction rate of the complex structure casting in the solidification process. Doctoral dissertation: Shenyang University of Technology, 2014. (in Chinese)

[15] Liu Jie, Bu Kun, Li Yong-yi, et al. Casting contraction analysis of turbine blade. Modern Manufacturing Engineering, 2008, 3 9-12.

[16] Jin Fangwei. Effect of graphite distribution morphology on performance of gray cast iron. Journal of Yunnan University, 2000,15, 6:139-141. (In Chinese)

This research was financially supported by the National Science Foundation for Distinguished Young Scholars of China (Grant No. 51525503) and the National Program for Support of Top-notch Young Professionals (Grant No. W02070184). 